THE POSTGRADUATE

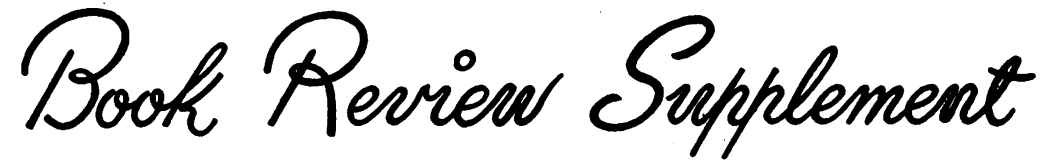

\section{THE MANAGEMENT OF BRONCHIAL ASTHMA}

By H. G. J. Herzheimer, M.D., L.R.C.P.ED., L.R.C.S.ED., L.R.F.P.S.GLAS. Pp. viii +107 , with I6 illustrations. London: Butterworth \& Co. 1952. 22s. 6d.

In this small book the author has adopted an individual approach and his conclusions are based on the results of his own experimental work. The first four chapters are concerned with definitions and diagnosis, the remaining 80 pages are devoted to advice on treatment. It includes a list of references and some typical case histories. The cost (22s. 6d.) seems to be excessive for so small a book, even by modern standards.

The problems that confront the enquiring practitioner interested in asthma are well set out, and the definitions and discussions of the underlying pathology are clear and comprehensible. The author tries to adopt a critical and scientific attitude to the many difficulties that arise in dealing with the management of asthmatic patients. Although it is evident that his conclusions are based on much hard work, he fails to achieve the high standard he has set himself. The effect is uneven, and in places confusing. Thus after discussing the method of specific desensitization by inhalation of increasing quantities of allergen in the form of an aerosol, he concludes by saying ' It is certain that more experience with the inhalation method is needed and that we are far from the possibility of its universal application. It is equally certain that it is one of our few reliable means of aetiological treatment, unfortunately yet restricted to a minority of cases.' (P. 83.) This paragraph is contradictory; furthermore, a method evidently still in the experimental stage is given too prominent a place in a book designed to help the practitioner. Later in the book the same method of treatment is referred to, stating ' Bronchial hyposensitization by aerosol inhalation offers the possibility of objective assessment.' (P. 97.) 'This is no doubt true, but he overlooks the fact that it is equally possible to assess the effect of treatment with the better-known method of subcutaneaus desensitization by means of exactly the same procedure, i.e., by spirographic tracings of the patient's respiration during exposure to an aerolized preparation of the allergen before and after treatment.

Those interested in asthma will find a great deal of value in this book, but its lack of discrimination limits its usefulness as a guide to practitioners.

\section{MODERN TRENDS IN GASTRO- ENTEROLOGY}

Edited by F. Avery Jones, M.D., F.R.C.P. Pp. xiii +831 , with 275 illustrations. London: Butterworth and Co. 1952. £5 5s.

The present rate of increment to our knowledge in medicine is so great that it is impossible for a single person to keep completely up to date with recent advances save in a comparatively limited sphere. Accordingly the publication of a book which sets out to survey all the new work in the immense field of gastro-enterology immediately promises to be of the greatest value, and one's expectation is heightened when the editor of the volume is so eminent an authority as Dr. Avery Jones. It can be said at once that such expectations are amply fulfilled, and that admiration and gratitude are plentifully due to the editor and his collaborators for this most interesting and stimulating volume.

The book is not intended to be a comprehensive? textbook of gastro-enterology. Its purpose ' is to bring together recent work in the gastro-enterological aspects of medicine and surgery,' and in this it eminently succeeds. The particular value of the work lies in the fact that the many sections cover not only advances in the practical clinical management of gastro-enterological disorders, but also much recent work on more theoretical aspects of the subject such as gastric secretion, fat absorption, pancreatic secretion and other subjects of fundamental physiological importance.

Written as they have been by experts in their fields the multiplicity of subjects have been lucidly and fully covered. Faced by such a distinguished collection of contributors as Witts, Aird, Norman Tanner, Illingworth, Cuthbert Dukes, Lloyd-Davies and Sherlock to mention but a few it is but invidious to single out any particular section for especial comment, but it is impossible to refrain from noting the outstanding articles by Belsey on diaphragmatic hernia, by Hardy and Brooke on ulcerative colitis and by Avery Jones on haematemesis and melaena.

Any detailed criticism of a work of this size is, of course, impossible and would be impertinent from a single reviewer. It is, perhaps, a little disappointing to find no reference at all to intestinal obstruction and only little to proctology, when 30 pages are devoted to diseases of the salivary glands, with no discussion of the modern work on the anatomy of the facial nerve in its relation to excision of tumours of the parotid gland. Further, 
in a brief but comprehensive discussion of the problems of electrolyte and fluid balance it is a pity that an apparently commendatory reference is made to Coller and Maddock's 'clinical rule' for the replacement of electrolyte deficits without reference to the fact that these same authors rescinded this rule in a paper written in 1944.

Such criticisms, however, in no way detract from the outstanding merit and value of this book, which cannot fail to interest all those concerned in this important branch of medicine. It is a volume to which physicians and surgeons will constantly turn for stimulus and information. It is a pity that we live in such times that 5 gns. must be expended in obtaining this magnificently produced book.

\section{STATISTICS FOR MEDICAL AND OTHER BIOLOGICAL STUDENTS}

By L. Bernstein, B.Sc., M.R.C.S., L.R.C.P., and M. Weatherall, M.A., D.M., B.Sc. Pp. xii + r8o. Edinburgh: F. \& S. Livingstone. 1952. I8s.

This book is an admirable introduction to statistics. There is a welcome emphasis on the need for planning throughout the whole course of an investigation, and the analysis of results is seen as merely the final step in the statistical discipline. However it seems to the reviewer that this book will appear too formidable to the general run of medical students. There is a tendency to approach problems from their more theoretical aspects rather than to lead gently up to them with examples of medical interest. This criticism derives from the ingrained prejudice that statistics are an independent discipline and that the medical student must therefore be wooed in order to participate. In factstatistical thinking should permeate medical thought, and as the authors point out, this must be achieved by the use of statistics as an integral part of all pre-medical and medical training. Statistics should not be taught as an independent subject, but should be introduced by every teacher whenever relevant.

\section{ORTHOPAEDIC NURSING}

By Mary Powell, S.R.N., M.C.S.P. Pp. xii + 400. Edinburgh: E. \& S. Livingstone. I 951. 25 s.

The quality of the training in orthopaedic nursing and after-care imparted by the staff of the Dame Agnes Hunt and Robert Jones Hospital at Oswestry is a by-word throughout the British Isles and, indeed, the Commonwealth. Miss Powell's profusely illustrated book reflects every aspect of the well-tried methods of the Oswestry School and provides a record which all tutor sisters and many nurses and orthopaedic surgeons will wish to read. Particular attention is paid to the correct use of those classical pieces of equipment, the Thomas bed knee splint and the Jones' double abduction frame, and to more recent techniques such as the Watson-Jones treatment of compression fractures of the lumbo-dorsal spine by hyperextension and the application of a plaster jacket.
The methods used in other centres, however, $\frac{2}{2}$ vary quite considerably from those collated by Miss Powell, and leading orthopaedic surgeons may be $c$ found who have abandoned the Thomas splint for: a fractured shaft of femur in favour of Hamilton- $\overrightarrow{\overrightarrow{\vec{s}}}$ Russell traction, who seldom use a frame for a tuberculous spine because they find an anterior or posterior plaster bed so simple, comfortable and $\overline{\bar{N}}$. effective or who for a variety of reasons never $\vec{\sigma}$ hyper-extend a compression fracture of the lumbar $\propto$ spine. But too wide a choice often makes for confusion, and for this reason Miss Powell's clear record of Oswestry's systematic teaching is all the more welcome.

K.I.N.

\section{MALIGNANT DISEASE AND ITS} TREATMENT BY RADIUM. VOL. 4

By Sir Stanford Cade, K.B.E., C.B., F.R.C.S., i M.R.C.P. 2nd Edition. Pp. xv +544 , with 785 illustrations. Bristol : John Wright \& Sons. $\frac{\omega}{6}$ 1952. 635 .

This fourth volume of Sir Stanford Cade's encyclopaedic monograph on malignant disease and its treatment by radium is of particular interest for 을 many reasons.

It includes chapters on subjects which have $\vec{z}$ always been particularly personal interests of the author's and some of these chapters reflect an experience which must be regarded as unique in if $\mathcal{e}_{0}$ extent. This particularly applies to bone sarcong ? (consideration of which is based on 164 patients figures), sarcomas of soft tissue and tumours of the testis. The volume is important, too, because it includes the author's views on malignant tumours of the skin, illustrated also by a very vast experience.

The author, in public debate, has established $a \stackrel{\varnothing}{\varrho}$ reputation for ardent advocacy and powerful $\overrightarrow{\vec{B}}$ rhetoric. His literary style can on occasion be just $\frac{\rho}{3}$ as forceful and dramatic; it is a tribute to his capacity for private judicial contemplation that he affords in this work a most balanced and unbiased judgment.

The volume includes chapters on the tumours of lymphoid tissue by George Lumb and F. M. Allchin, on the leukaemias by B. W. Windeyer and J. W. Stewart, and on intracranial tumours by Denis Williams, Wylie McKissock and Jackson Richmond.

This volume, like its predecessors, is eminently readable and the vast amount of factual knowledge which it contains is arranged with masterly generalship. The production is of the highest order and $\mathcal{N}$ the illustrations have a perfect clarity both in respect $N$ of microphotographs and $\mathrm{X}$-ray reproductions. N Colour has been liberally employed and many $\omega$ original diagrams are very valuable. The work as a whole will be read with profit and retained for 0 frequent reference by surgeons, pathologists and radiotherapists. It can safely be regarded as a $\stackrel{?}{?}$ standard account of the whole field of treatment of $T$ malignant disease today and it contributes sub- 0 stantially to the natural history of cancer and to $\mathbb{\mathbb { D }}$ descriptive and statistical oncology.

I.A. 